\title{
Is paediatric endotracheal suctioning by nurses' evidence based? An International Survey
}

\author{
Laura L. Rad RN, BSc (Nurs), Clinical Research Nurse Team Leader ${ }^{1}$ | \\ Bernie Carter RN, PhD, Professor, Director ${ }^{2,3}$ (1) । \\ Martha A. Q. Curley RN, PhD, FAAN, Ruth M. Colket Endowed Chair 4,5,6 \\ Beverley Copnell RN, PhD, Associate Clinical Professor ${ }^{7}$ । \\ Lyvonne N. Tume RN, PhD, Reader (Associate professor) ${ }^{8,9}$ (
}

\author{
${ }^{1} \mathrm{PICU}$, Alder Hey Children's Hospital, \\ Liverpool, UK \\ ${ }^{2}$ Children's Nursing, Faculty of Health, Social \\ Care and Medicine, Edge Hill University, \\ Ormskirk, UK \\ ${ }^{3}$ Children's Nursing Research Unit, Alder Hey \\ Children's Hospital NHSFT, Liverpool, UK \\ ${ }^{4}$ Pediatric Nursing, Children's Hospital of \\ Philadelphia, Philadelphia, Pennsylvania \\ ${ }^{5}$ Department of Family and Community \\ Health, School of Nursing, University of \\ Pennsylvania, Philadelphia, Pennsylvania \\ ${ }^{6}$ Department of Anesthesia and Critical Care \\ Medicine, Perelman School of Medicine, \\ Philadelphia, Pennsylvania \\ ${ }^{7}$ School of Nursing and Midwifery, La Trobe \\ University, Melbourne, Victoria, Australia \\ ${ }^{8}$ School of Health and Society, Centre for \\ Health Sciences Research, University of \\ Salford, Manchester, UK \\ ${ }^{9} \mathrm{PICU}$, Alder Hey Children's Hospital, PICU, \\ Liverpool, UK
}

Correspondence

Lyvonne N. Tume, Child Health School of Health and Society, University of Salford, Manchester, UK.

Email: I.n.tume@salford.ac.uk

\begin{abstract}
Background: Endotracheal suction (ETS) is essential in intubated patients to prevent tube occlusion and is one of the most common nursing interventions performed in intensive care.

Aims and objectives: To explore how paediatric ETS practices reflect evidence-based practice (EBP) recommendations in paediatric intensive care units (PICU) worldwide.

Study design and methods: A cross-sectional electronic survey linked to a real patient suction episode. Nurses completed the survey following a recent ETS episode. Evidence-based practice (EBP) was defined based on four of the American Association for Respiratory Care (AARC) best evidence recommendations: preoxygenation before suction, use of a suction catheter no more than half the diameter of the tracheal tube, shallow depth of suction, and the continuous suction applied upon withdrawal of the catheter. Participants included PICU nurses who performed ETS in children (0-17 years) excluding preterm neonates.

Results: Four hundred forty-six complete surveys were received from 20 countries. Most nurses $(80 \%, 367 / 446)$ reported that their units had local guidelines for ETS. The most common reason for suctioning (44\%) was audible/visible secretions. Over half of ETS episodes (57\%) used closed suction. When exploring the individual components of suction, $63 \%(282 / 446)$ of nurses pre-oxygenated their patient prior to suction, $71 \%$ (319/446) suctioned no further than $0.5 \mathrm{~cm}$ past end of the endotracheal tube (ETT), 59\% (261/446) used a catheter no more than half the diameter of the ETT, and $78 \%(348 / 446)$ used continuous negative pressure. $24 \%$ of nurses gave patients an additional bolus of sedative, analgesic, and/or muscle-relaxant medication prior to suction; this decision was not related to the child's history of instability with suction, as there was no significant difference in those who reported patients had a history of being unstable with suction $(P=.80) .26 \%$ (117/446) of nurses complied with all four EBP components in the reported suctioning episode.
\end{abstract}


Conclusions: Considerable variation in paediatric endotracheal suctioning practices exists internationally. Although most nurses applied single components of evidence-based recommendations during ETT suctioning, just a quarter applied all four elements.

Relevance to clinical practice: Nurses' need to consider and strive to apply EBP principles to common nursing interventions such as ETS.

\section{KEYWORDS}

child, evidence-based practice, neonate, nursing practice, suctioning

\section{1 | INTRODUCTION}

Endotracheal suction (ETS) is essential for any child with an endotracheal tube (ETT), its primary aim being the removal of secretions and prevention of obstruction of the child's airway. ${ }^{1}$ Failure to clear secretions can result in an obstructed or occluded ETT, which, if untreated, will impair oxygenation and ventilation and gas exchange, potentially resulting in cardiopulmonary arrest. ${ }^{2}$ Although essential, ETS has established adverse effects including bradycardia, atelectasis, hypertension, hypoxaemia, and cardiac arrest, ${ }^{3}$ and the risk of these complications may be increased in high-risk children. ${ }^{4}$ The most recent published guidelines for ETS are those by the American Association of Respiratory Care (AARC) in $2010,{ }^{5}$ but many of these recommendations are based on limited evidence and extrapolated from adult data. In 2015, Tume and Copnell ${ }^{6}$ reviewed the paediatric ETS evidence, finding limited evidence for many aspects of ETS. Therefore, the aim of this study was to explore international nursing practices in ETS and to compare this to the best-available evidence on ETS.

\section{2 | METHODS}

We conducted an international, cross-sectional electronic survey of paediatric intensive care unit (PICU) nurses. Nurses were asked to complete the survey after performing ETS on their assigned child patient (age termed to 17 years) and to consider this patient when responding to the survey questions. The survey was initially open for a 5-day period in November 2016 but re-opened for another 5-day period at the end of 2016 to increase response rates. Nurses who had completed the survey in the first round did not complete round 2 . We excluded suctioning on pre-term infants or adults and any suctioning not performed by nurses.

\section{1 | Survey development and refinement}

Two previous survey instruments developed in the United States and Australia (Curley, 1996 and Copnell, 2005) were examined; questions were updated to reflect current evidence. Duplicate questions were removed, and additional questions were reviewed and discussed by

\section{What is known about this topic}

- Endotracheal suctioning is one of the most common nurse-performed procedures in intensive care units.

- The application of best evidence-based principles to nursing other nursing interventions has been shown to be variable.

\section{What this paper adds}

- An international perspective on nurses' use of evidencebased principles during endotracheal suctioning in critically ill children.

- Evidence that despite published recommendations, there is considerable variability in nurses' use of evidencebased practice when performing endotracheal suctioning in children. the study team. Eight iterations of the e-survey tool were built using Survey Monkey (San Mateo, California) and reviewed by the expert panel (authors: L. R., M. Q. C., B. C., L. T., B. C.) before consensus was reached. Face validity was established after testing on five PICU nurses with different levels of education and experience on the English version survey. The revised tool was pilot tested again ( $n=54$ nurses) in one large UK PICU. The final tool consisted of 54 questions in five main domains: (a) non-identifiable patient demographics; (b) preparation for suction; (c) during the suction; (d) post suction interventions; and (e) non-identifiable nurse demographics (Supplementary file 1-Survey Instrument).

The e-survey was translated into eight different languages by bilingual international PICU colleagues who generously gave their time to support this international survey (English into French, Spanish, Portuguese, Italian, Finnish, Slovakian, Dutch, and Latvian) using a recognized cultural translation and adaptation process. ${ }^{7}$ These translators also predominantly acted as the country lead. All questions were multiple choice or close-ended to avoid the need for back-translation of responses. In 
total, 22 versions of the survey instrument were built (one per country who agreed to take part). A translation record was kept for all languages so that all survey responses could be combined into one data set for analysis. Once countries agreed to participate, the country lead, who took responsibility for ensuring ethical requirements were fulfilled in their country and determined the best method for survey distribution in their country, was sent a link to the survey for distribution within their country. In some countries, the survey distribution was via a professional society, for others the survey link was sent from the individual to PICU nursing leads. Instructions for the survey completion were sent to country leads regarding the inclusion and exclusion criteria and instructions that the nurse who performed the suction should complete the survey as close to the suctioning episode as possible to reduce recall bias.

PICUs were only identifiable by country; no other unit-identifiable data were collected. Nurses completed the e-survey as soon as possible (within the same day) after their selected suction episode to ensure their account of the episode was as accurate as possible.

\section{2 | Ethical approval}

Ethical approval was gained through the University of Central Lancashire (STEMH 346, July 2015). In addition, the study was endorsed by both the UK Paediatric Intensive Care Society Study Group (PICS SG) and the European Society of Paediatric and Neonatal Critical Care (ESPNIC). Once countries agreed to participate, a country lead ensured ethics approval requirements were met in their country. As the survey collected only anonymized and non-identifiable data, only Finland, Italy, Singapore, and Canada required further ethics approval, and these were gained. In North America, the American Association of Critical Care Nursing (AACCN) and the Canadian Association of Critical Care Nursing (CACCN) deferred additional review and sent the survey link to their paediatric nurse members. For all participants, completion of the survey implied consent.

\section{3 | Defining evidence-based practice}

Pragmatically for the purpose of this study, the study team defined evidence-based practice (EBP) for paediatric suctioning, based on four of the AARC (2010) best evidence recommendations ${ }^{5}$ and the latest review and recommendations for paediatric suction, ${ }^{6}$ as pre-oxygenation prior to suction (evidence grade $2 \mathrm{~B}$ ), use of a suction catheter no more than half the diameter of the ETT (evidence grade $2 \mathrm{C}$ ), the depth of suction to the length of the ETT or no more than $0.5 \mathrm{~cm}$ beyond (shallow suction) (evidence grade $2 \mathrm{~B}$ ), and the application of continuous suction pressure upon withdrawal of the catheter (no evidence grade). Our survey aimed to capture both planned and unplanned suction episodes; because of this our definition of EBP did not include other recommendations (eg, suction indications, use of saline) that might apply only to planned (non-urgent) suctioning episodes. We believe the four recommendations we chose to define EBP suction practice were applicable regardless of situation (planned or urgent) and all are recommended based on some evidence. We categorized patients into low- and high-risk groups for analysis. High- risk patients in this survey were defined as follows: congenital heart disease requiring single ventricle repair, traumatic brain injury (TBI) with intracranial hypertension, and high-frequency oscillatory ventilation (HFOV).

\subsection{Data analysis}

Data were exported from SurveyMonkey (San Mateo, California) in a CSV file into Microsoft Excel (Microsoft Corp, Washington DC) and then into IBM SPSS v22 (IBM Corp., Armonk, New York) for analysis. Most of the survey data were categorical and are presented descriptively as percentages, or for continuous variables with median (interquartile range [IQR]) or mean (SD) depending on the normality of the data. Non-parametric tests were used to test both the relationship and correlation between the categorical variables. The dependent variable was the use of EBP (as previously defined as meeting the four criteria) and the independent variables tested were nurse experience (under or over 5 years), specialist paediatric intensive care qualification, the presence of a local unit suction guideline, and an English-speaking country. Chi-square test and Spearman's rank test were used to test these relationships. Spearman $\rho$ was used for categorical data to examine whether there was a correlation between the use of evidence-based guidelines and key variables. A $P$ value of $<.05$ was considered significant and two-tailed tests were used.

\section{3 | RESULTS}

In total, 446 questionnaires were completed in nine different languages by participants from 20 countries. The highest responding countries were United States (27.1\% 121/446), United Kingdom (14.3\% 64/446), Spain (10.5\% 47/446), The Netherlands (8.5\% 38/446), and Italy (8.1\% 36/446) (Supplementary File 2). By continent, Europe had the largest response with $56 \%(248 / 446)$ of the total respondents, North America had $33 \%$ of the total respondents (146/446), Asia 6\% (28/446), Australia 4\% (20/446), and South America 1\% (4/446) of the total.

\section{1 | Nurse demographics}

Participating nurses were mostly from general PICUs (49.6\%, 221/446), with fewer $(35 \%, 156 / 446)$ from combined cardiac and general PICUs; the remaining nurses came from combined PICU/NICU (10.5\%, 47/446), paediatric cardiac PICU (3.8\%, 17/446), and adult/paediatric mixed ICU (1.1\%, 5/446). The mean number of PICU beds per unit was 19 (SD 8.28). The mean PICU nurse experience was 9 years (SD 7.9), and $54 \%$ of nurses $(242 / 446)$ held a PICU specialist qualification.

\section{2 | Patient demographics}

Most of the children suctioned (60\%, 267/446) were less than 1 year of age and were ventilated with respiratory failure or infection (Supplementary File 3). 


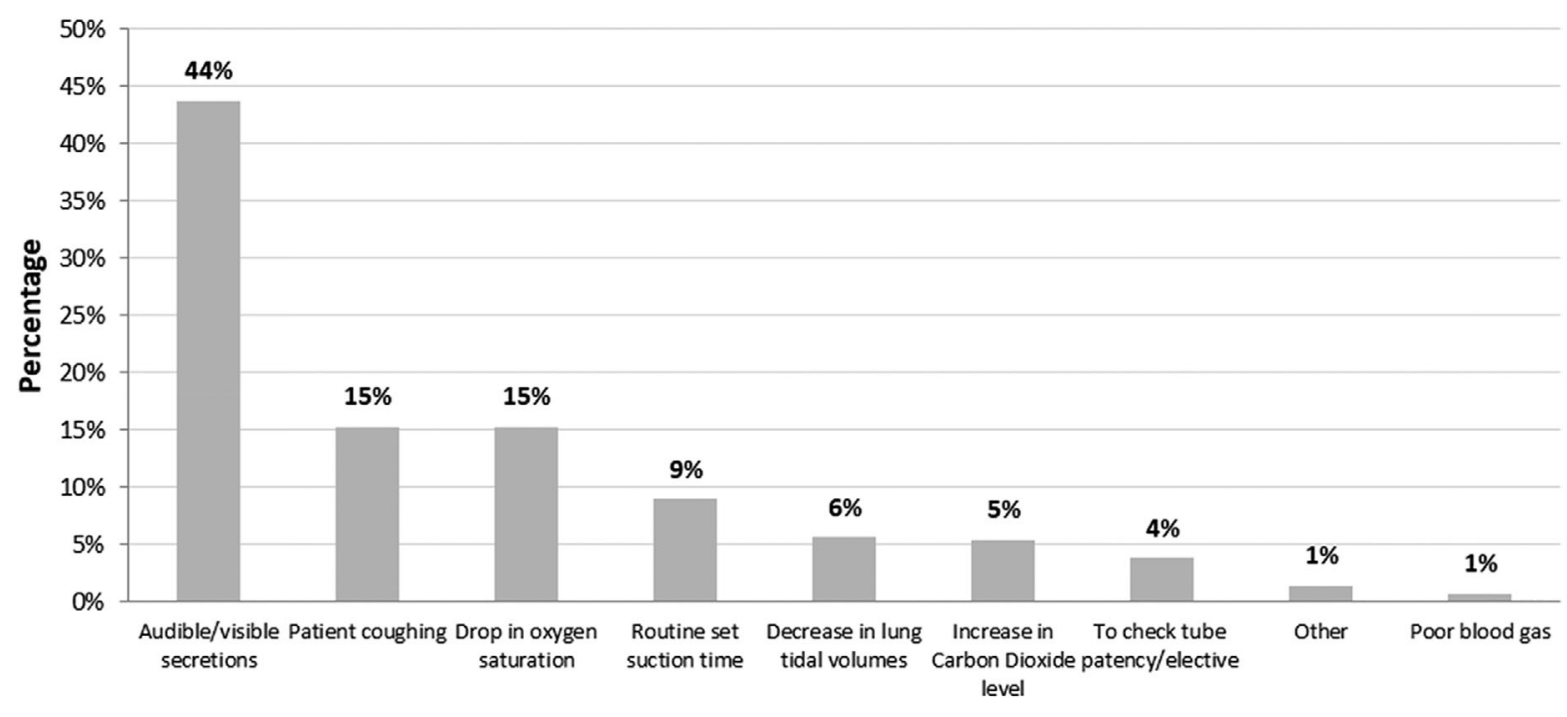

Reason for Suction

FIGURE 1 Nurse cited reasons for endotracheal suctioning

\begin{tabular}{|c|c|c|c|c|}
\hline Suction practice & $\begin{array}{l}\text { Closed suction } \\
\%\end{array}$ & $(n=252)$ & $\begin{array}{l}\text { Open suction } \\
\%\end{array}$ & $(n=245)$ \\
\hline \multicolumn{5}{|l|}{ Use of gloves } \\
\hline Clean & $81 \%$ & $(204 / 252)$ & $46 \%$ & $(111 / 245)$ \\
\hline Sterile & $6.3 \%$ & $(16 / 252)$ & $49 \%$ & $(119 / 245)$ \\
\hline No gloves & $13 \%$ & $(32 / 252)$ & $5.7 \%$ & $(14 / 245)$ \\
\hline \multicolumn{5}{|l|}{ Suction depth } \\
\hline To end of ETT & $46 \%$ & $(116 / 252)$ & $46 \%$ & $(112 / 245)$ \\
\hline $0.5 \mathrm{~cm}$ past end of ETT & $29 \%$ & $(73 / 252)$ & $21 \%$ & $(51 / 245)$ \\
\hline $1 \mathrm{~cm}$ past end of ETT & $13 \%$ & $(33 / 252)$ & $14 \%$ & $(34 / 245)$ \\
\hline $2 \mathrm{~cm}$ past end of ETT & $2 \%$ & $(5 / 252)$ & $4.1 \%$ & $(10 / 245)$ \\
\hline$>2 \mathrm{~cm}$ past the end of ETT & $2.4 \%$ & $(6 / 252)$ & $3.7 \%$ & $(9 / 245)$ \\
\hline I do not know & $7.5 \%$ & $(19 / 252)$ & $12 \%$ & $(29 / 245)$ \\
\hline \multicolumn{5}{|l|}{ Suction pressure method } \\
\hline Continuous & $80 \%$ & $(201 / 252)$ & $76 \%$ & $(187 / 245)$ \\
\hline Intermittent & $20 \%$ & $(51 / 252)$ & $23 \%$ & $(57 / 245)$ \\
\hline I do not know & $0 \%$ & $(0 / 252)$ & $0.4 \%$ & $(1 / 245)$ \\
\hline Number of suction passes & $\begin{array}{l}\text { Median: } 2 \\
\text { (IQR 1-2) }\end{array}$ & & $\begin{array}{l}\text { Median: } 2 \\
\text { (IQR 1-2) }\end{array}$ & \\
\hline \multicolumn{5}{|l|}{ Saline instilled } \\
\hline Yes & $20 \%$ & $(50 / 252)$ & $58 \%$ & $(143 / 245)$ \\
\hline No & $80 \%$ & $(202 / 252)$ & $42 \%$ & $(102 / 245)$ \\
\hline Saline volume instilled & $\begin{array}{l}\text { Median: } 1 \mathrm{~mL} \\
\text { IQR: 1-2 }\end{array}$ & & $\begin{array}{l}\text { Median: } 1 \mathrm{~mL} \\
\text { IQR: } 1-2\end{array}$ & \\
\hline
\end{tabular}

TABLE 1 Comparison of open vs closed suction procedures

Abbreviations: ETT, endotracheal tube; IQR, interquartile range. 


\section{3 | Prior to suctioning}

The top three reported indications for performing suction were audible/visible secretions (44\% 195/446), patient coughing (15\% 68/446), and a reduction in arterial oxygen saturations (15\% 68/446). Nine percent of nurses reported suctioning at a pre-set time, regardless of clinical need (Figure 1). In total, 59\% (259/443) reported pre-suction oxygen saturations $\left(\mathrm{SaO}_{2}\right)$ were above $95 \%$ and $76 \%(335 / 443)$ stated they were $90 \%$ or above. Only $4.7 \%(6 / 443)$ reported that $\mathrm{SaO}_{2}$ saturations were between $70 \%$ and $80 \%$ pre-procedure and the remaining $1.6 \%(7 / 443)$ stated that $\mathrm{SaO}_{2}$ were less than $70 \%$. The lowest reported $\mathrm{SaO}_{2}$ was $25 \%$. We did not ask for specific patient diagnoses and therefore cannot relate which proportion of these are children with cyanotic congenital heart disease.

The median fraction of inspired oxygen $\left(\mathrm{FiO}_{2}\right)$ was 0.35 (IQR 0.3-0.5). Just over half of nurses $(63 \%, 282 / 446)$ stated that they pre-oxygenated the child prior to suction. Around a quarter $(24 \%$, 106/446) stated that they administered an extra intravenous (IV) bolus of medication prior to suctioning. In total, 181 boluses were reported by the 106 nurses who gave an extra drug bolus and over half $(55 \%, 89 / 161)$ of these boluses were sedation; $27 \%$ (44/161) were given analgesics; $11 \%$ were given muscle relaxants; and the remaining $6.2 \%(10 / 161)$ reported administering a local anaesthetic. These percentages did not change in patients who had been reported as being previously unstable during ETS.

\section{4 | During suctioning}

Most patients were conventionally ventilated $(92 \%, 412 / 446)$ and, in around half $(55 \%, 225 / 412)$ of these, closed circuit suction was used; $45 \%$ (187/412) were open suctioned. Of those children receiving HFOV, most $(79 \%, 27 / 34)$ had closed circuit suction, with
$21 \%(7 / 34)$ being open suctioned. Overall, in $57 \%(252 / 446)$ of suctioning procedures and regardless of ventilator mode, nurses used closed-circuit ETS.

\subsection{Closed-circuit suctioning practice}

Of the 244 responses with closed suction, the size of the catheter used was identified in $87 \%(212 / 244)$ of cases; in $13 \%(32 / 244)$ of cases, the catheter size was reported as "not known." A catheter of half the size of ETT diameter was used in 51\% (108/212) of cases; $25 \%(53 / 212)$ used a catheter that was larger and 24\% (50/212) used a catheter less than half of the ETT diameter. For most of these patients (81\%, 204/252), nurses stated that they used clean gloves during the suction procedure. Nearly half the nurses (46\%, 118/252) reported suction depth as being to the end of the ETT, with the next most common suctioning depth being $0.5 \mathrm{~cm}$ past the end of the ETT (29\%, 73/252). Saline was instilled into the ETT during their suction episode in a fifth $(20 \%, 50 / 252)$ of the closed ETS episodes; $1 \mathrm{~mL}$ was the median volume reported (IQR 1-2 mL).

\subsection{Open suctioning}

For the patients who were open suctioned (239/446 responses), $98 \%$ $(235 / 239)$ identified the size of catheter used; $1.6 \%$ (4/239) did not know the catheter size. The correct catheter size for ETT was used in $58 \%(136 / 235)$ cases, whereas $26 \%(60 / 235)$ used a catheter larger than recommended and $17 \%(39 / 335)$ used a catheter smaller than recommended. Glove usage in open suction episodes was split between clean $(45 \%, 111 / 244)$ and sterile gloves $(49 \%, 119 / 224)$ with the remaining $5.7 \%(14 / 244)$ not wearing gloves. Nearly half $(46 \%$, $111 / 245$ ) reported suction depth as being to the end of the ETT, with

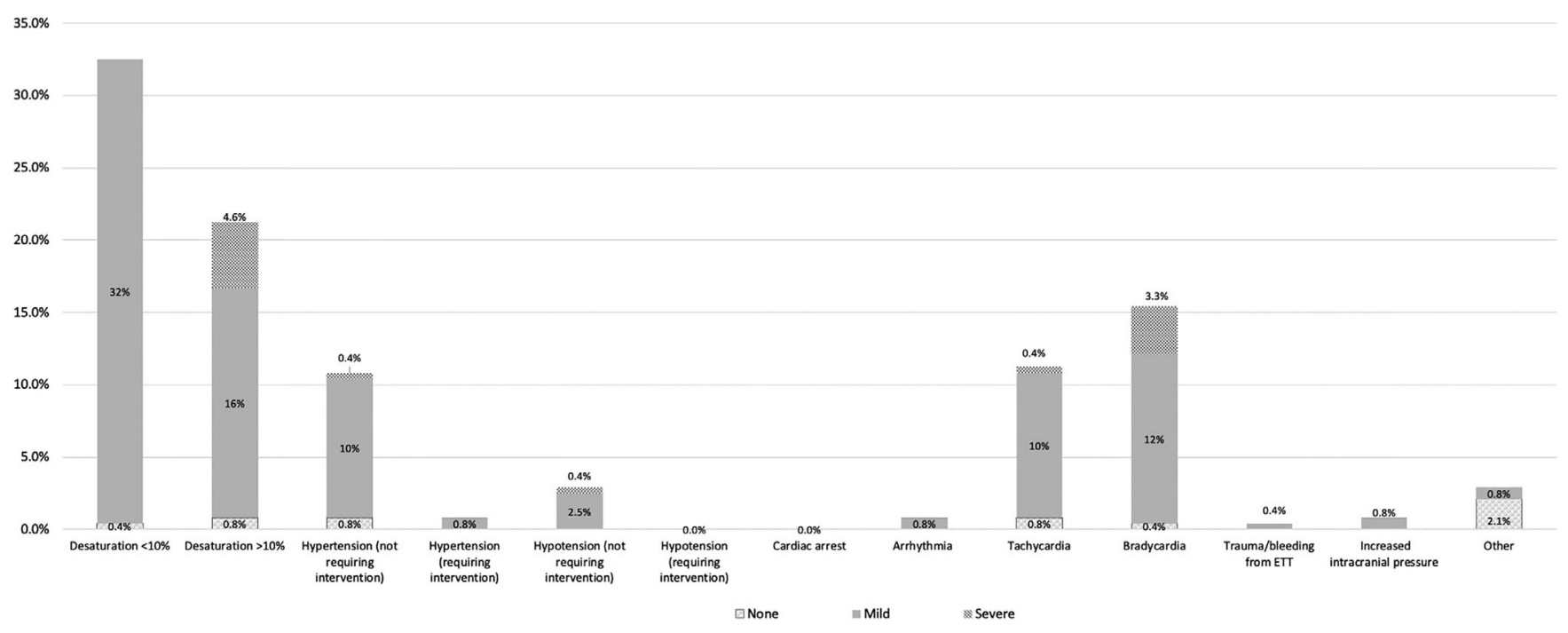

FIGURE 2 Deterioration sign associated with suction 
TAB LE 2 Compliance with evidence-based practice (EBP) across all suction episodes

\begin{tabular}{|c|c|c|}
\hline Evidence-based practice criteria & $\%$ & $(n=446)$ \\
\hline \multicolumn{3}{|l|}{ Pre-oxygenation } \\
\hline Yes & $63 \%$ & 282 \\
\hline No & $37 \%$ & 164 \\
\hline \multicolumn{3}{|l|}{ Suction depth } \\
\hline To end of endotracheal tube & $47 \%$ & 211 \\
\hline $0.5 \mathrm{~cm}$ past end of endotracheal tube & $24 \%$ & 108 \\
\hline $1 \mathrm{~cm}$ past end of endotracheal tube & $13 \%$ & 59 \\
\hline $2 \mathrm{~cm}$ past end of endotracheal tube & $2.7 \%$ & 12 \\
\hline $\begin{array}{l}\text { More than } 2 \mathrm{~cm} \text { past the end of } \\
\text { endotracheal tube }\end{array}$ & $3.1 \%$ & 14 \\
\hline I do not know/unanswered & $9.4 \%$ & 42 \\
\hline \multicolumn{3}{|l|}{ Recommended size suction catheter used } \\
\hline Yes & $59 \%$ & 261 \\
\hline No & $42 \%$ & 185 \\
\hline \multicolumn{3}{|l|}{ Suction pressure type } \\
\hline Continuous & $78 \%$ & 348 \\
\hline Intermittent & $22 \%$ & 98 \\
\hline \multicolumn{3}{|l|}{ Evidence-based practice } \\
\hline $\begin{array}{l}\text { Yes (pre-oxygenated }+ \text { used correct } \\
\text { catheter }+ \text { correct suction depth }+ \\
\text { continuous pressure) }\end{array}$ & $26 \%$ & 117 \\
\hline No & $74 \%$ & 329 \\
\hline
\end{tabular}

Note: Bold text and values represent areas within EBP definition.

$21 \%(51 / 245)$ reporting depth at $0.5 \mathrm{~cm}$ past the end of the ETT. In over half $(58 \%, 143 / 245)$ of the open ETS episodes, saline was instilled during the suction episode; the median volume instilled was $1 \mathrm{~mL}$ (IQR 1-2 mL). Use of saline instillation was significantly higher if an open suction technique was used $(P<.001)$ compared to closed suction (Table 1).

\subsection{Deterioration associated with suctioning}

The majority $(65 \%, 290 / 446)$ of nurses perceived that their patient showed no deterioration during or after ETS but 32\% (143/446) perceived mild deterioration and $3 \%(13 / 446)$ perceived their child suffered severe deterioration. Of those who stated that some form of deterioration occurred, the most common (50\%, 78/156) was oxygen desaturation less than $10 \%$ from baseline; 33\% (51/156) reported desaturation of greater than $10 \%$ from baseline, 15\% (27/156) reported tachycardia, and 24\% (37/156) reported bradycardia. There were no reports of cardiac arrest. In total, 240 different deterioration signs were reported (Figure 2). There was no significant difference between open and closed suction, when all deterioration events were combined (mild and severe): 67\% (130/194) with open vs $63 \%$ $(160 / 252)$ with closed suction $(P=.44)$.

\section{8 $\quad$ After suctioning}

Nearly one-fifth of nurses, $18 \%$ (81/446), stated they altered at least one ventilation setting after suction. Of those who did, 90 changes to ventilator settings were reported, as some nurses changed more than one setting. The most common alteration was $\mathrm{FiO}_{2}$, accounting for $73 \%(66 / 90)$ of all changes. Most nurses (78\%, 348/446) did not perform any recruitment manoeuvre after suction. Few nurses $4.7 \%$ (21/446) administered some medications after suction but, for those who did, the most common medication reported was a sedative drug.

\section{9 | Evidence-based ETS practice}

Most $(83 \%, 367 / 442)$ respondents stated their unit had written guidance for suctioning; but of the $16.9 \%$ (75/442) who said their unit did not, there were conflicting responses from the same unit, indicating a lack of knowledge of unit guidance. Overall, $26 \%$ (117/446) of suctioning episodes met our definition for EBP. When exploring the individual components of ETS, 63\% (282/446) of nurses pre-oxygenated their patient prior to suction, $71 \%$ (319/446) suctioned no further than $0.5 \mathrm{~cm}$ past end of the ETT, $59 \%(261 / 446)$ used a catheter no more than half the diameter of the stated ETT, and 78\% (348/446) used continuous pressure on catheter withdrawal (Table 2). Just over one quarter, $26 \%$ $(117 / 446)$ of nurses complied with all four components we defined as EBP in the reported suctioning episode.

No relationship was found between compliance with EBP and nurse experience ( $>5$ years) $(P=.253$ ) or specialist PICU nurse education $(P=.171)$. Nor was there any relationship between application of EBP and the presence of local suction guidelines $(P=.487)$ or between English-speaking countries and non-English speaking $(P=.587)$. In addition, there was no relationship between suctioning the "higher risk" patients (single ventricle repair, TBI or HFOV) and nurses' use of $\operatorname{EBP}(P=.839)$. In the higher risk groups, there was also no significant relationship between nurse experience ( $>5$ year) $(P=.200)$, specialist nurse education $(P=.307)$, presence of local guidelines $(P=.87)$, or an English-speaking country $(P=.407)$ to the application of EBP.

\section{DISCUSSION}

This study is the largest and only international survey of nurses' suction practice in paediatric intensive care, which specifically links a real patient suction episode to the nurses' practice.

Nurse experience or PICU education did not enhance the use of evidence-based suction practice. This contrasts with the findings of a survey of ICU nurses in Tanzania, ${ }^{8}$ which found that nurses with ICU education had significantly higher knowledge of endotracheal suctioning. An Italian survey of adult intensive care nurses' knowledge of best EBP endotracheal suction ${ }^{9}$ revealed a significantly lower knowledge level in nurses with $<5$ years' experience compared to those with 
more experience. However, nurses' knowledge does not always translate into application to clinical practice; and we found no relationship between nurse experience or specialist ICU education and their use of EBP.

It may be that unit "culture" and practices around suction influence nurses' practice more than experience and education, as has been reported in other studies exploring guidelines in critical care settings. ${ }^{10}$ Regardless of their PICU experience or education, just over a quarter of PICU nurses applied all four elements of EBP during their suction. The theory of planned behaviour argues that the subjective norms of a group significantly impact on the intention to perform behaviour ${ }^{11}$ Nursing as a profession is heavily driven by group norms and unspoken rules, ${ }^{12}$ which may override the perceived importance and value of EBP guidelines. An updated systematic review ${ }^{13}$ reports research utilization by nurses to be higher in graduates and those attending in-service or conferences. Although we did not collect data on these factors, specialist PICU nurse education did not significantly affect the use of EBP. We hypothesized that since most guidance is published in English, this may affect the use of EBP with non-English speaking nurses more likely to not follow EBP, but we did not find this. Other work has shown that the presence of local unit guidelines and poor adherence could be linked to perceived barriers such as resistance to change, insufficient training, and lack of support from higher authority. ${ }^{10}$ A large Australian survey of 800 nurses ${ }^{14}$ found nurses were more likely to use research evidence if it was easily accessible; we hypothesized that the presence of local unit guidelines might increase the application of EBP but our findings did not support this hypothesis. However, it is acknowledged that these local unit guidelines themselves may not be evidence based. In this study, nurses reported that lack of support from other (senior) staff was a barrier to the use of EBP, but this finding was not further examined in our study. Much of the evidence that underpins the latest paediatric suctioning guidance is weak and some of it is extrapolated from adults or preterm infants. These may be among the reasons why nurses are not following recommendations, but this needs further exploration.

In terms of nurses' use of individual components of evidencebased suctioning, our study confirms that of other work ${ }^{15}$ except for the higher reported use of routine suctioning (at pre-set times). A Canadian multicentre survey ${ }^{16}$ also found a large proportion of nurses and respiratory therapists suctioned routinely rather than as required, a practice that does not reflect current best evidence recommendations; they also found that staff routinely instilled saline, despite the evidence not recommending this. We found saline instillation was significantly higher if an open suction method was used compared to closed suction; no other studies have reported this. A qualitative study of 12 Australian PICU nurses showed practice was very variable regarding saline instillation and nurses relied on knowledge of individual patients' conditions, clinical knowledge and experience, and the local setting expectations for this practice. ${ }^{17} \mathrm{~A}$ recent systematic review and evidence grading of existing guidelines regarding saline use ${ }^{18}$ concluded that it is not recommended, but this was limited by the quality of evidence.
Almost $20 \%$ of our survey suction episodes were on high-risk patients. A prospective observational study in $2017^{15}$ reported deterioration events in high-risk neonates with single ventricle lesions after cardiac surgery as high as $9 \%$ and found a significantly higher rate of adverse events with open suction, although we did not find any difference. This may be explained because we combined both mild and severe events and all patients, not just the high-risk children. However, a recent prospective observational study in an Australian PICU found an adverse event rate of $22 \%$ of suctions and these were not associated with age, diagnosis, or index of mortality score. ${ }^{19}$ Statistical modelling revealed that saline instillation was significantly associated with an increased risk of arterial desaturation.

\subsection{Strengths and limitations}

There are some limitations to our study that warrant mentioning. Although we asked nurses to relate their suction episode to a specific child, the data were self-reported, cannot be verified, may be affected by recall bias, and the nurses' perception of deterioration is subjective. The possibility of selection bias may also reflect better motivated nurses and we cannot know whether this is representative of all PICU nurses. Additionally, we combined both mild and severe events and all patient deterioration events, which may have impacted our findings. Nurses' selection of patients to include may also have induced bias towards the less sick children and in those there was no deterioration. Our pragmatic definition of EBP criteria is based on the 2010 AARC recommendations, much of which lacks robust paediatric evidence, and this may have impacted on our results. However, we used the most common criteria for EBP and "best practice" across all patient types, based on these published recommendations. The overrepresentation from North America and Europe may introduce some bias and limit generalizability. Due to our survey distribution methods, and an unknown denominator, we are unable to calculate a response rate. Despite these limitations, we believe by conducting the survey in this way and relating nursing practice to a specific patient we have captured a realistic international picture of paediatric suctioning practice by nurses.

\section{5 | CONCLUSIONS}

This is the largest international survey of nurses' suctioning practice of critically ill children; as such it provides important new information about nurses' use of EBP recommendations during suction. We found that despite these widely available published guidelines (in 2010), the evidence was not being utilized in practice by all nurses at the bedside. Further work needs to explore how nurses use evidence-based recommendations, why guidelines are not followed for endotracheal suctioning, and how guidelines have been implemented into units. 


\section{ACKNOWLEDGEMENTS}

We would like to acknowledge the Paediatric Intensive Care Society, The European Society of Neonatal and Paediatric Intensive Care (ESPNIC), Canadian Critical Care Nurses Association (CCCNA), and The American Association of Critical Care Nurses (AACCN). We are also indebted to the lead person for each country, and especially those bilingual clinicians who translated the survey into the local language. United Kingdom-Laura Rad, Lyvonne Tume; Denmark-Janne Weis; FranceFrederic Valla, Caroline Richard; Spain-Omar Rodriguez Forner, Yolanda López, Antonio Rodríguez Núñez; Netherlands-Erwin Ista, Piet L Leroy, Martin Kneyber; Belgium-Francoise Martens, Dirk Danschutter; Switzerland-Grandjean Chantal, Anne-Sylvie Ramelet; Finland, Kristina Piironen; Slovakia, Vlad Hol; United States-Martha A Q Curley; Canada-Karen Dryden- Palmer, Christine Halfkenny-Zellas (CACCN), Daniel Garros; Australia-Bev Copnell; Singapore-Ya Nee Poh; Mauritius-Ram Mudhoo; Latvia-Reinis Balmaks; Germany-Ilona Weidner; Portugal-Cristina Camilo; Brazil, Chile, Argentina, ColumbiaMavilde Pedreira; Italy-Orsola Gawronski; India-Nikhil Tiwari. This study was unfunded although it was undertaken while undertaking PhD studies and the tuition fees were funded by School of Nursing, University of Central Lancashire.

\section{ORCID}

Bernie Carter (iD) https://orcid.org/0000-0001-5226-9878 Lyvonne N. Tume (D) https://orcid.org/0000-0002-2547-8209

\section{REFERENCES}

1. Morrow B, Futter M, Argent A. Effect of endotracheal suction on lung dynamics in mechanically ventilated paediatric patients. Aust J Physiother. 2006;52(2):121-126.

2. Gardner DL, Shirland L. Evidence-based guideline for suctioning the intubated neonate and infant. Neonatal Netw. 2009;28(5):281-302.

3. Pirr SM, Lange M, Hartmann C, Bohnhorst B, Peter C. Closed versus open endotracheal suctioning in extremely low-birth-weight neonates: a randomized, crossover trial. Neonatology. 2013;103(2): 124-130.

4. Kohlhauser C, Bernert G, Hermon M, Popow C, Seidl R, Pollak A. Effects of endotracheal suctioning in high-frequency oscillatory and conventionally ventilated low birth weight neonates on cerebral hemodynamics observed by near infrared spectroscopy (NIRS). Pediatr Pulmonol. 2000;29(4):270-275.

5. American Association for Respiratory Care. AARC clinical practice guidelines. Endotracheal suctioning of mechanically ventilated patients with artificial airways 2010. Respir Care. 2010;55(6):758-764.

6. Tume LN, Copnell B. Endotracheal suctioning of the critically ill child. J Pediatr Intensive Care. 2015;04(2):56.

7. Endacott R, Benbenishty J, Seha M. Preparing research instruments for use with different cultures. Intensive Crit Care Nurs. 2010;26(2):64-68.
8. Mwakanyanga ET, Masika GM, Tarimo EAM. Intensive care nurses' knowledge and practice on endotracheal suctioning of the intubated patient: a quantitative cross-sectional observational study. PLoS One. 2018;13(8):e0201743. https://doi.org/10.1371/journal.pone.0201743.

9. Negro A, Ranzani R, Villa M, Manara D. Survey of Italian intensive care unit nurses' knowledge about endotracheal suctioning guidelines. Intensive Crit Care Nurs. 2014;30(6):339-345.

10. Eldh AC, Vogel G, Söderberg A, Blomqvist H, Wengström Y. Use of evidence in clinical guidelines and everyday practice for mechanical ventilation in Swedish intensive care units. Worldviews Evid Based Nurs. 2013;10(4):198-207.

11. Appleby BE. Implementing guideline-checklists: evaluating health care providers intentional behaviour using an extended model of the theory of planned behaviour. J Eval Clin Pract. 2019;25(4):664-675.

12. Street AF. Inside Nursing: A Critical Ethnography of Clinical Nursing Practice. New York: State University of New York Press; 1992.

13. Squires JE, Hutchinson AM, Boström A, O'Rourke HM, Cobban SJ, Estabrooks CA. To what extent do nurses use research in clinical practice? A systematic review. Implement Sci. 2011;6(1):21.

14. Retsas A. Barriers to using research evidence in nursing practice. J Adv Nurs. 2000;31(3):599-606.

15. Tume LN. Patterns of instability associated with endotracheal suctioning in infants with single-ventricle physiology. Am J Crit Care. 2017;26(5):388-394.

16. Leddy R, Wilkinson JM. Endotracheal suctioning practices of nurses and respiratory therapists: how well do they align with clinical practice guidelines? Can J Respir Ther. 2015;51(3):60-64.

17. Schultz J, Cooke M, Long D, Mitchell M. Normal saline and lung recruitment with paediatric endotracheal suction: a review and critical appraisal of practice recommendations. Dimens Crit Care Nurs. 2020; 39(6):321-328.

18. Schults JA, Cooke M, Long D, Mitchell M. "When no-one's looking," the application of lung recruitment and normal saline instillation with paediatric endotracheal suction: an exploratory study of nursing practice. Aust Crit Care. 2018;32(1):13-19. https://doi.org/10.1016/j. aucc.2018.03.002.

19. Schults JA, Long D, Mitchell M, et al. Adverse events and practice variability associated with paediatric endotracheal suction: an observational study. Aust Crit Care. 2019;33:350-357. https://doi.org/10. 1016/j.aucc.2019.08.002.

\section{SUPPORTING INFORMATION}

Additional supporting information may be found online in the Supporting Information section at the end of this article.

How to cite this article: Rad LL, Carter B, Curley MAQ, Copnell B, Tume LN. Is paediatric endotracheal suctioning by nurses' evidence based? An International Survey. Nurs Crit Care. 2021;1-8. https://doi.org/10.1111/nicc.12644 